\title{
On pandemics and pivots: a COVID-19 reflection on envisioning the future of medical education
}

Heeyoung Han ${ }^{1}$, Amy Clithero-Eridonn ${ }^{2}$ Manuel João Costa ${ }^{3}$, Caitriona A. Dennis ${ }^{4}$, J. Kevin Dorsey ${ }^{1}$, Kulsoom Ghias ${ }^{5}$, Alex Hopkins ${ }^{1}$, Kauser Jabeen ${ }^{5}$, Debra Klamen', Sophia Matos ${ }^{1}$, John D. Mellinger', Harm Peters $^{6}$, Suzanne Pitama ${ }^{7}$, C. Leslie Smith', Susan F. Smith ${ }^{8}$, Boyung Suh', Sookyung Suh ${ }^{1}$ and Marko Zdravković, ${ }^{9} 10$

${ }^{1}$ Southern Illinois University School of Medicine, Springfield, IL, ${ }^{2}$ University of New Mexico, Albuquerque, NM, USA, ${ }^{3}$ School of Medicine, University, Braga, Portugal, ${ }^{4}$ University of Leeds, Leeds, UK, ${ }^{5}$ Aga Khan University, Karachi, Pakistan, ${ }^{6}$ Charité, Universitätsmedizin Berlin, Berlin, Germany, ${ }^{7}$ University of Otago, Christchurch, New Zealand, Imperial College School of Medicine, London, UK, ${ }^{9}$ University Medical Centre Maribor, Maribor, and ${ }^{10}$ Faculty of Medicine, University of Ljubljana, Ljubljana, Slovenia

The required adjustments precipitated by the coronavirus disease 2019 crisis have been challenging, but also represent a critical opportunity for the evolution and potential disruptive and constructive change of medical education. Given that the format of medical education is not fixed, but malleable and in fact must be adaptable to societal needs through ongoing reflexivity, we find ourselves in a potentially transformative learning phase for the field. An Association for Medical Education in Europe ASPIRE Academy group of 18 medical educators from seven countries was formed to consider this opportunity, and identified critical questions for collective reflection on current medical education practices and assumptions, with the attendant challenge to envision the future of medical education. This was achieved through online discussion as well as asynchronous collective reflections by group members. Four major themes and related conclusions arose from this conversation: Why we teach: the humanitarian mission of medicine should be reinforced; what we teach: disaster management, social accountability and embracing an environment of complexity and uncertainty should be the core; how we teach: open pathways to lean medical education and learning by developing learners embedded in a community context; and whom we teach: those willing to take professional responsibility. These collective reflections provide neither fully matured digests of the challenges of our field, nor comprehensive solutions; rather they are offered as a starting point for medical schools to consider as we seek to harness the learning opportunities stimulated by the pandemic.

Key Words: COVID-19 pandemic, Medical education, Forecasting, Distance education, Social responsibility

\section{Introduction}

The pandemic caused by the severe acute respiratory syndrome coronavirus 2 is reshaping medical education practice in a manner unprecedented in modern times, and with previously unimaginable alacrity. Medical education is facing a disruptive and forced deviation from its existing values, standards, and practices. As examples of this, it can be quickly recognized that many non-urgent, community-based patient consultations have shifted to telemedicine platforms and rapidly
Received: August 13, 2021 • Revised: August 13, 2021 - Accepted: October 6, 2021 Corresponding Author: Heeyoung Han (https://orcid.org/0000-0002-7286-2473) Department of Medical Education, Southern Illinois University School of Medicine, 913 North Rutledge Street, PO Box 196, Springfield, IL 62794-9638, USA

Tel: +1.217.545.8536 Fax: +1.217.545.0120 email: hhan@siumed.edu
Korean J Med Educ 2021 Dec; 33(4): 393-404 https://doi.org/10.3946/kjme.2021.207 eISSN: 2005-7288

(C) The Korean Society of Medical Education. All rights reserved. This is an open-access article distributed under the terms of the Creative Commons Attribution Non-Commercial License (http:// creativecommons.org/licenses/by-nc/3.0/), which permits unrestricted non-commercial use, distribution, and reproduction in any medium, provided the original work is properly cited. 
navigated previously existing adoption barriers. This has created a whole new domain in which to educate and regulate patient-learner and teacher-learner interactions essentially overnight. In addition, final-year medical students were redeployed as dispensers rather than learners so as to support the stressed and overburdened healthcare system, and/or allowed to graduate early to help decompress the healthcare workload [1]. Such quantum adjustments would have been unimaginable on any similar scale a year ago.

Such forced changes due to the pandemic crisis are challenging but also represent a critical opportunity for the evolution of the medical education field. In a recent editorial commentary, Gibbs [2] highlighted that what the pandemic has provided is the critical moment to stop and think deeply and reflectively about the field and its future. Yesterdays' practices and the assumptions on which they have been founded may no longer befit-for-purpose. While there have been numerous innovations in medical education in recent decades, the overall structure has been treated in practice, if not intent, as largely unalterable for many years [3]. Since medical education forms the foundation for the delivery of a product essential to personal and societal well-being, and since the social environment itself continues to change under a variety of pressures in knowledge, technology, economics, and social conditions, the educational process itself should not be treated as a perfected entity, but rather as one accountable to changing societal needs through ongoing reflexivity [4]. We thus find ourselves in a potentially transformative learning phase for the field of medical education [5].

This group aimed to identify critical questions conducive to deliberate and critical, collective reflection regarding our present medical education practices and their underlying assumptions, and to envision the future of medical education globally.

The group engaged with this project was formed from an international medical education group, the ASPIRE Academy. The ASPIRE-to-Excellence Award program was set up by the Association for Medical Education in Europe to recognize excellence in education [6]. The representatives of the schools which received the award for excellence in education in one or more areas established the ASPIRE Academy in order to accelerate the transition to excellence in healthcare education, and to enhance health globally [7]. The ASPIRE Academy has conducted a monthly virtual meeting, designated the iXII1) Meeting, since March 2020. The 18 educators participating in this discussion are from seven different countries (Germany, Pakistan, New Zealand, Portugal, Slovenia, United Kingdom, and United States). The group started discussions on the general topic of the future medical education; the focus of these reflections were centered on several specific themes as the group was convened, given the coronavirus disease 2019 (COVID-19) pandemic.

Four major themes worthy of reflection in line with the above-stated goals were identified, and formed the foundation for the group's deliberations: why we teach, what we teach, how we teach, and whom we teach.

\section{Why we teach}

Historically, most health care systems and their supporting educational programs have been based on a limited linear framework, specifically a sickness-based model. While preventive care strategies have achieved

1) iXII stands for "International eXtra Innovation Investigators". XII is a group convened to discuss medical education innovation and brainstorm the future of medical education, which was originally initiated at the Southern Illinois University School of Medicine under the leadership of Dr. Debra Klamen in 2004. 
some penetrance in contemporary health care, in many settings, there continues to be a requirement for patient volume to sustain the financial health of most medical centers. Recent events that diminished patient flow in clinics and hospitals during the pandemic lockdown have made it obvious that the goals of income generation and a healthy society may not be properly aligned. This disruption was perhaps felt most acutely in those nations and economies where a direct or indirect fee for service model serves as the foundation for the interaction between patient and physician [8]. In short, this economic based contract for care delivery has not been in alignment with the presumed covenantal commitment of the medical profession to overall population health.

Medical education has been sustained within this paradoxical paradigm of profiting from, in some ways, a sustaining burden of disease rather than the promotion of health. In many countries, an academic center's income sources depend heavily on clinical services, and its attendant educational priorities are likely and resultingly biased in favor of specialized professional care for those who can afford it in the tertiary hospital, rather than cost effective preventive care for society as whole [3]. Healthcare and medical education systems are inseparably linked and often dependent on patient care derived revenues, deployed within the confines of a regulated healthcare workforce equation. The public health limitations and disparity issues the pandemic has made accentuated highlight that it is time to challenge ourselves with our dependence on this model of educational and care delivery, and envision an alternative future. What might this future be? How do we prepare our future physicians to make change? Should medical educators work on reshaping the interdependency between the healthcare and education sectors?

It seems timely to deconstruct this cycle as its effects have been magnified in the pandemic context. Medical education can amplify its primary humanitarian mission focused on the social good of justly delivered healthcare [9]. Academic centers and health care sectors should collaborate to redefine the healthcare system so as to reward promotion of preventive care and public health rather than to exclusively provide disease diagnoses and treat end stage processes. Community engagement is critical to promote this health-based model, incorporating those being served as collaborators, partners, and $\mathrm{co}^{-}$-creators in preventive care. The widespread use of telemedicine precipitated by social distancing pressure offers the opportunity to improve preventive care, wellbeing, and the health of our patients at a lower societal net cost, as is underway in Malaysia and other countries [10,11]. If physician consultations are easier and less time consuming for patients, this could foster an improved working relationship between patient and physician, creating more time to collaborate on common preventive health problems requiring behavior modification such as diabetes, hypertension, and weight management [12].

Coincident with such efforts, the nigh-prohibitive cost of medical education should be addressed in order to move toward the value of the social good of healthcare. Contemporary medical education requires all medical learners to take years of general training before focusing on a specialty. To compensate for the cost of medical training, many students may feel the need to select a specialty based on greater compensation and the attendant business model where illness generates income. To address this systemic problem, new healthcare and education systems have been considered. Norcini [13] proposed a new model of education around "microcredentials" focusing on certain medical practices. This model would allow the medical education system to efficiently develop a less expensive healthcare work- 
force focused on patients' and community needs. Dewan and Norcini [14] proposed guaranteed minimum training for a license to practice in the United States, such that all US medical students could train to the point of foundational practice capability without the fear of not gaining an otherwise residency position simply to practice. This kind of blue-sky thinking in medical education can disrupt the perpetuated interdependence between healthcare business delivery sectors and medical education, and promote evolution toward a more egalitarian medical education process, and associated care delivery.

\section{What we teach}

During the pandemic, ironically, many physicians had to stay home while there were desperate needs for healthcare workers in COVID-19 hot spots [8]. Another dysfunctional circumstance in areas of high disease burden was the dissuasion of sick patients from access to a healthcare facility unless it was an emergency. Such approaches resulted in unprecedented collateral health damage with advanced disease progression and even mortality related to limited access. Such unintended consequences of pandemic mitigation demonstrate the substantial gap between community need and health care system delivery capability. Many such contexts overlapped with areas of high socioeconomic deprivation, accentuating already apparent healthcare disparities. The pandemic has made it clear that many medical schools, broadly speaking, are unable and disincentivized to develop physicians who can be responsive to communities at greater risk of worse outcomes. In order to address societal needs, the content of medical curricula should be significantly changed to address the gap that recent events have brought into focus. We identify three areas for this change toward community and public health: disaster management, social accountability and complexity, and capacity to manage uncertainty through multiple paradigms.

\section{Disaster management}

One urgent area that desperately needs national and global attention is disaster management. The World Health Organization defines a disaster as "a severe disruption, ecological and psychosocial, which greatly exceeds the coping capacity of the affected community" [15]. In response to a pandemic, individuals and agencies, such as healthcare professionals, community workers, local governments, and nonprofit organizations share responsibilities for disaster management processes. The task involves more than understanding the pathophysiology of COVID-19. It involves education on how to address a pandemic the creation of teams, leadership, resource and supply chain management, appropriate skills development, and communication with the community. Recent studies on the COVID-19 epidemic unanimously identified deficiencies in public health emergency preparedness, disaster coordination, interdisciplinary cooperation, and medical ethics in medical education [16,17]. Additionally, the public reluctance to vaccinate has been one of the critical barriers amid the epidemic.

One way to increase the effectiveness of disaster management is to invest in disaster preparedness, as constantly underscored by the United Nations and humanitarian organizations [18]. Disaster management is not new in medicine and other professional education but is rarely part of a medical curriculum [19]. Disaster preparedness requires not only having the requisite supplies on hand, but also having effective leadership and personnel cross-trained to contribute skills outside of their defined specialty during a disaster [19]. 
Contemporary medical education is aligned with health care systems that focus on field specialization. The exclusiveness of each specialty is limiting the basic and common functions and scope of medicine, and proves in the pandemic to be more self-serving than oriented to the societal need and good [13]. Physicians are capable within their specialties, but struggle serving as a generalist within a pandemic. This irony of specialization leaves the fundamental and general needs of the public potentially unaddressed.

\section{Social accountability and complexity}

There is an evident disconnect between what communities need and how health care professionals are trained [20]. In addition to technical proficiency, health professionals need to be both person and communityoriented to improve population health. Health professional schools have an ethical responsibility to their communities to produce practitioners who can address the public's broad interests and specifically social issues relating to the public's health and wellbeing, which are often full of complexity. Inherent within this responsibility is for the schools to identify societal needs and demonstrate results [5].

Despite these social priorities, there exists an inappropriate epistemology of competencies [21,22], whereby contemporary medical education has reduced the importance of complexity by defining competence with simplified and check-list driven tasks, predicated on linear knowledge development and performance assessments favoring clean and easily measurable learning objectives. The medical education curriculum has also historically been relatively weak on the complex themes of health equity and medical ethics, including indigenous health, minority health, migrant health, refugee health, care of sexual and gender minority groups, poverty, rurality, and mental health [23]. For example, despite incarceration being an epicenter for chronic illness, infectious disease, mental illness, and substance abuse, medical education programs rarely teach correctional health [24]. Students and residents are under-prepared to understand the multi-faceted impacts on health equity and local community health inherent in such subpopulations, particularly when government health directives are based solely on dominant population norms and fail to incorporate regard for minority and underrepresented communities [25].

Medicine is a complex social practice. The core competencies that the medical education curriculum teaches cannot be appropriately focused on performing over-simplified and sterilely itemized tasks detached from a community and relational context, but should navigate complexity in order to address community and population health needs. Humanities, social sciences, community health education, and ethics should be introduced early on in education to frame their importance, and should be embedded in the learning experiences of students across courses, allowing the student to grow in their "wisdom" and character-founded application of knowledge and technical skill. These topics should be put to use daily to solve problems, and not viewed as simply additional bits of isolated knowledge to be acquired or covered in curricular outlines.

Learning about communities by developing within communities themselves, embedded as a learner within the complexity and the diversity of their health care needs, should become a primary driver of curriculum in medical education. A lack of social accountability in contemporary medical education has occurred in part because of the lack of in-depth relationships between students, schools, and their surrounding communities, which is in fact required for the community to feel confident and invested in the medical school [26]. 
Without situation in a community, complexity can not become the teachable object in a medical education curriculum. It seems imperative for medical schools to work alongside communities, to learn how they might contribute to community initiatives and innovation. Medical schools need to demonstrate ongoing commitment and sustainability to their local constituencies. It is these stakeholders, after all, that constitute the patient body they need for training, and reflect their achievement of competency or lack thereof in healthcare outcomes. This evolution would help to ensure graduates have the clinical and cultural competencies necessary to be accountable to communities with the greatest needs, and to have the tools which will be necessary to proactively reduce inequities in future pandemics or other disaster environments [27].

\section{Uncertainty through multiple paradigms}

Medical knowledge in the current medical education curriculum is typically dominated by a traditional biomedical paradigm (biochemistry, pathology, pharmacology, and so forth). The pandemic has reminded us of the nature of uncertainty in health care practice and the need for diverse paradigms in medicine [28]. Ilgen et al. [29] noted that experienced physicians tend to be more tolerant of uncertainty and accept the dynamic aspect of medicine where a contemporary diagnosis and treatment is an ongoing process for problem identification. COVID-19 is still a relatively poorly understood disease that has no proven, ubiquitously successful treatments at the time of this writing. What is more, the sudden flood of COVID-19 related publications has made it unmanageable to follow the research findings in the field. Additionally, there has been an associated diminished quality of the research findings published in high impact journals in the rush to provide current information, with an unprecedented number of $\mathrm{re}^{-}$ tractions in this short period of time [30,31]. This uncertainty provides the profession an opportunity to self-reflect on our reliance on one specific medical paradigm in our education of future physicians [28].

There is more than one form of medicine and more than one way of teaching and practicing medicine [22]. Health and disease can be explained differently based on different medical paradigms. While biomedical treatments rely primarily on pharmaceuticals and surgery, complementary, alternative, and integrative medicine strategies similarly rely on internal (botanical medicine, nutraceuticals, mindfulness, and foods as medicine) and external manipulations of the body (acupuncture, massage, and body movements like yoga and tai chi) as tools in promoting health. For example, Qigong, one form of traditional Asian medicine focusing on mind-body exercise has been reported as effective for the prevention, treatment, and rehabilitation for respiratory illness including COVID-19 in China [32]. It is not that we are rejecting the current utilization of biomedicine, which has had profound effects on disease burden and life expectancy in recent decades. Indeed, the vaccination strategies derived from this model may be the most important measure that curbs the pandemic's progress in the months to come. Rather, we are inviting and considering other views to broaden our therapeutic opportunities with an unknown disease, allowing us to address unprecedentally-complex health issues. Exploring paradigms that broaden the capacity of medical trainees to respond in uncertain environments with strategies to promote wholistic wellness, in a fashion complementary to pharmacologic and extirpative strategies, could expand the toolkit of our trainees as they navigate uncertainty. Included in this category would be the imperative highlighted by the pandemic to faciliatate and support trainees in building the character qualities and disciplines that correlate with high- 
reliability function in uncertain environments [33,34].

\section{How we teach}

The pandemic has provided the impetus to reflect on the process of how medical education is delivered. Medical education is rapidly moving toward online learning, especially in pre-clinical curricula [35]. Online education seems likely to remain mainstream if not normative even after the pandemic. The question now is how can students and educators optimally benefit from the digital experience? This disruptive change in medical education delivery requires delving into how educators teach and how effective the current delivery system is. We identify two areas for reflection: open lean medical education and learning by working in a community.

\section{Open lean medical education}

The recent movement to online learning in preclinical medical education does not simply indicate the migration of the curriculum to a virtual environment but creates the possibility of open lean medical education [36]. If lectures are delivered in an online format, why not share resources with learners in other schools, ideally taught and facilitated by the most competent instructors with reference to both content and educational skill? Why should all medical schools put time and resources to create and deliver the same content? As there is foundational medical knowledge that all medical learners should learn [37], preclinical medical education could evolve further toward "open" learning shared beyond the individual medical school boundaries. Moreover, the influx of new information is enormous in medicine and the information needs to be curated at a system level [20]. This problem is universal and shared by many medical schools.
Institutional collaboration to curate new information and provide an organized, standardized, and shared curriculum of foundational medical knowledge for all medical schools may open a new paradigm toward a lean medical education structure for preclinical medical education, including some of its interprofessional components. In some developing countries with a scarcity of resources and qualified faculty, these open online resources developed and curated by a collective set of institutions would be fundamentally helpful to address the shortage of healthcare providers $[3,38]$. This new method of medical education would de-monopolize preclinical medical education, and improve accessibility for all learners with less regard to socioeconomic status.

\section{Learning by working in a community}

The ultimate added value of medical education is access to clinical practices and socialization into the healthcare system, which are not fully replaceable with online learning. Medical education should revisit the power of place, i.e., place-based pedagogy. Place-based pedagogy along with rooted experiential learning requires specific learnable objects tied to specific places and communities that would not be taught otherwise, such as free community clinic service learning and global health experiences [39].

A positive educational aspect during the pandemic has been that medical education expanded from a simulation lab, or a doctor's office in clerkships toward real communities where authentic healthcare issues reside and in fact clamored for attention. As discussed in the earlier section, if social accountability is a desirable goal of medical education, how it is taught should be aligned with the context of the objective. Medical schools need to train physicians in their future environments including outside the four walls of the classroom and clinic. To do this, it seems imperative to extend the 
training environment beyond the campus and to build in-depth relationships with the community [26].

To facilitate students' workplace learning [40,41], students' roles should shift from learners to workers, which would change all social and environmental dynamics of their learning. In many countries there is an assumption that medical students should learn before working which excludes the educational value of working to learn. Why should medical education not allow students to take an appropriate level of responsibility in their clinical learning environments as a means of professional development, and allow them to experience the realities of professional commitment? On-the-job training is well-established in workplace learning [42]. Paid on-the-job training is available for firefighters' and emergency medical technicians' programs. Learning in the absence of work responsibilities can be unsatisfying, in that students may be relegated to remotely peripheral positions in the learning community [43]. The loss of opportunities to develop the skills of working in a healthcare system, interacting with peers, patients, healthcare teams, and communities, is critical [44]. As long as we can provide adequate oversight for medical learners, the integration of concomitant working and learning is something that medical education should revisit as a means to enhance student experience, engagement, and professional formation.

Interestingly, there is a movement, driven by the needs of coping with the current pandemic, to challenge the traditional notion of "learner only" student activity. In the United Kingdom, the Medical Schools Council has published very clear guidelines defining the role of medical students volunteering in the workplace [45]. In Portugal and Pakistan, medical schools started involving students as volunteer workers in response to the pandemic. Future evaluation of these initiatives will demonstrate the impact of volunteering on student learning and the development of professional identity. In the meantime, it is apparent that the pandemic is blurring the line between working to learn and learning to work in medical education, and this should be a very constructive tension for medical educators to manage both pedagogically and socially in the future.

\section{Whom we teach}

A recent study in Singapore about students' preference for re-entering clinical settings during the COVID-19 pandemic reported that one third of the medical students did not want to return to clinical work while two-thirds of them were willing to [46]. There would be reasonable situations where appropriate personal protective equipment was not available, or where students had health conditions that would prevent their safe return. However, the study noted differences between the group characteristics: those who were willing to return had higher internal motivation and professional responsibility than the other group. Whom do we teach? Whom have we chosen to teach? Should we not select and teach those who are willing to take professional responsibility, and how might we become more effective in doing so?

Medical schools have traditionally prioritized high prior academic performances as the most important inclusion criteria for admission, even though there have been many efforts to promote holistic admissions [47]. This protocol for admissions has been justified through longitudinal studies demonstrating that students selected through more holistic pathways are more likely to complete the course of study successfully [48]. Using high grades as the primary inclusion criterion favors (mainly white) students from middle to high income families who have typically benefited from the highest quality educational opportunities [49]. The medical 
school environment then reinforces the culture of these educational institutions, which supports ongoing success within this context.

The profession of medicine is based on a social contract, which requires professional altruism and integrity, as well as scientific knowledge [50]. Medical schools ought to select future physicians who will be willing to embrace the professional responsibilities needed in diverse and underserved communities, and especially so during a disaster. This can be achieved through prioritizing selection of a diverse workforce characterized by strong internal rather than external motivation, a highly developed sense of social responsibility rather than individually focusedachievement, and capability in understanding and communicating with diverse communities. The attributes for such a workforce are likely different from those that were prioritized in the past [51].

\section{Conclusion}

Medical education must continue to question itself and transform. As a social, scientific, and service construct, medicine is always a "child of her age". In the course of the past year, the pandemic has challenged paradigms of how medical education should be delivered. Medical educators have a responsibility to make the most of this opportunity as a potentially transformative selfreflective moment that further advances medicine and its service to society. COVID-19 provides a novel opportunity for the medical education field to be disoriented from traditional norms and traditions, and re-oriented to wiser standards and practices that propel the field toward greater societal responsiveness and accountability. Collective efforts should be made to ensure things do not "snap back" to the way they have always been done simply because they were normative and habitual in our practice, and thereby the potential of the pandemic to disruptively stimulate growth and reform be lost.

Instead, explicit justification of those aspects of contemporary medical education and its various components worthy of preservation should be articulated with forethought if they are to remain. Such critical analysis will capitalize on the "teachable moment" the current situation presents to us as a unique opportunity of our age. This crucial inflection point, in which a global health crisis has intersected for the first time, at least on this scale, with modern scientific medicine, has the potential to create space for the innovation needed in improving the preparation of the next generation of physicians. The four themes discussed in this paper are distinct, yet circulate around a core idea of embracing the humanity, complexity, uncertainty, and evolving nature of human development and health. They provide neither completed thoughts nor absolute solutions; rather they are offered as a starting point for medical schools to consider how to derive long-term benefit from the short-term changes required of medical education within the current COVID-19 environment.

\section{ORCID:}

Heeyoung Han: https://orcid.org/0000-0002-7286-2473; Amy Clithero-Eridon: https://orcid.org/0000-0002-1652-3725; Manuel João Costa: https://orcid.org/0000-0001-5255-4257; Caitriona A. Dennis: https://orcid.org/0000-0002-9218-3558; J. Kevin Dorsey: https://orcid.org/0000-0001-5673-9662; Kulsoom Ghias: https://orcid.org/0000-0002-8709-7428; Alex Hopkins: https://orcid.org/0000-0002-2438-3240; Kauser Jabeen: https://orcid.org/0000-0003-2497-7847; Debra Klamen: https://orcid.org/0000-0001-5471-6635; Sophia Matos: https://orcid.org/0000-0002-2918-5534; 
John D. Mellinger: https://orcid.org/0000-0002-4230-311X;

Harm Peters: https://orcid.org/0000-0003-1441-7512;

Suzanne Pitama: https://orcid.org/0000-0002-1664-0518;

C. Leslie Smith: https://orcid.org/0000-0002-4285-8780;

Susan F. Smith: https://orcid.org/0000-0003-4807-4837;

Boyung Suh: https://orcid.org/0000-0002-8702-814X;

Sookyung Suh: https://orcid.org/0000-0003-1417-6800;

Marko Zdravković: https://orcid.org/0000-0002-0033-7071

Acknowledgements: None.

Funding: None.

Conflicts of interest: No potential conflict of interest relevant to this article was reported.

Author contributions: Conception or design of the work: $\mathrm{HH}$; data collection: not applicable; data analysis and interpretation: not applicable; drafting the article: all of the authors; critical revision of the article: $\mathrm{HH}, \mathrm{AC}, \mathrm{JM}$, MZ; and final approval of the version to be published: all of the authors.

\section{References}

1. Di Donata V, McKenzie S. Fresh out of medical school, young Italian doctors are being fast-tracked to the coronavirus frontline. CNN. March 30, 2020. https:// edition.cnn.com/2020/03/30/europe/italy-young-doctors-c oronavirus-intl/index.html. Accessed August 5, 2021.

2. Gibbs T. The COVID-19 pandemic: provoking thought and encouraging change. Med Teach. 2020;42(7): 738-740.

3. Frenk J, Chen L, Bhutta ZA, et al. Health professionals for a new century: transforming education to strengthen health systems in an interdependent world. Lancet. 2010;376(9756):1923-1958.

4. Giddens A. Modernity and self-identity: self and society in the late modern age. Cambridge, UK: Polity Press; 1991.
5. Mezirow J. Learning to think like an adult: core concepts of transformation theory. In: Mezirow JD, ed. Learning as Transformation Critical Perspectives on a Theory in Progress. San Francisco, USA: Jossey-Bass; 2000:3-33.

6. Harden RM, Roberts TE. ASPIRE: international recognition of excellence in medical education. Lancet. 2015;385(9964):230.

7. Hunt D, Klamen D, Harden RM, Ali F. The ASPIRE-to-Excellence Program: a global effort to improve the quality of medical education. Acad Med. 2018; 93(8):1117-1119.

8. Neighmond P. Growing costs and shrinking revenues squeeze hospitals as they brace for coronavirus. National Public Radio. 2020 April 6. https://www.npr.org/sections/ health-shots/2020/04/06/828108255/growing-costs-and-s hrinking-revenues-squeeze-hospitals-as-they-brace-for-cor onav. Accessed August 5, 2021.

9. Bleakley A. Invoking the medical humanities to develop a \#MedicineWeCanTrust. Acad Med. 2019;94(10): 1422-1424.

10. Suleiman AB. The untapped potential of Telehealth. Int J Med Inform. 2001;61(2-3):103-112.

11. Tuckson RV, Edmunds M, Hodgkins ML. Telehealth. N Engl J Med. 2017;377(16):1585-1592.

12. Rush KL, Hatt L, Janke R, Burton L, Ferrier M, Tetrault M. The efficacy of telehealth delivered educational approaches for patients with chronic diseases: a systematic review. Patient Educ Couns. 2018;101(8): 1310-1321.

13. Norcini J. Is it time for a new model of education in the health professions? Med Educ. 2020;54(8):687-690.

14. Dewan MJ, Norcini JJ. We must graduate physicians, not doctors. Acad Med. 2020;95(3):336-339.

15. World Health Organization, Division of Mental Health. Psychosocial consequences of disasters: prevention and management. Geneva: World Health Organization; 1992.

16. Sun $\mathrm{QH}, \mathrm{Su} \mathrm{Y}$. The practice of cultivating medical 
students' sense of social responsibility under the background of disaster rescue. Med Teach. 2020;42(7): 834.

17. Yang DY, Cheng SY, Wang SZ, et al. Preparedness of medical education in China: lessons from the COVID-19 outbreak. Med Teach. 2020;42(7):787-790.

18. James LE, Welton-Mitchell C, Noel JR, James AS. Integrating mental health and disaster preparedness in intervention: a randomized controlled trial with earthquake and flood-affected communities in Haiti. Psychol Med. 2020;50(2):342-352.

19. Nasiri A, Aryankhesal A, Khankeh H. Leadership in limbo: characteristics of successful incident commanders in health sector of a disaster-prone country. Int J Health Plann Manage. 2019;34(4):el495-e1509.

20. Wartman SA. The empirical challenge of 21st-century medical education. Acad Med. 2019;94(10):1412-1415.

21. Boyd VA, Whitehead CR, Thille P, Ginsburg S, Brydges R, Kuper A. Competency-based medical education: the discourse of infallibility. Med Educ. 2018;52(1):45-57.

22. Tilburt J, Geller G. Viewpoint: the importance of worldviews for medical education. Acad Med. 2007; 82(8):819-822.

23. Pitama SG, Palmer SC, Huria T, Lacey C, Wilkinson T. Implementation and impact of indigenous health curricula: a systematic review. Med Educ 2018 Jun 22 [Epub]. https://doi.org/10.1111/medu.13613.

24. Simon L, Tobey M. A national survey of medical school curricula on criminal justice and health. J Correct Health Care. 2019;25(1):37-44.

25. Ross BM. Critical pedagogy as a means to achieving social accountability in medical education. Int J Crit Pedagog. 2015;6(2):169-186.

26. Strasser R, Worley P, Cristobal F, et al. Putting communities in the driver's seat: the realities of community-engaged medical education. Acad Med. 2015;90(11):1466-1470.
27. Pitama S, Beckert L, Huria T, et al. The role of social accountable medical education in addressing health inequity in Aotearoa New Zealand. J R Soc N Z. 2019;49(supl):58-71.

28. Choe YH. Preparing for medical education after the COVID-19 pandemic: insightology in medicine. Korean J Med Educ. 2021;33(3):163-170.

29. Ilgen JS, Eva KW, de Bruin A, Cook DA, Regehr G. Comfort with uncertainty: reframing our conceptions of how clinicians navigate complex clinical situations. Adv Health Sci Educ Theory Pract. 2019;24(4):797-809.

30. Mehra MR, Desai SS, Ruschitzka F, Patel AN. Retracted: Hydroxychloroquine or chloroquine with or without a macrolide for treatment of COVID-19: a multinational registry analysis. Lancet. 2020 May 22 [Epub]. https://doi.org/10.1016/S0140-6736(20)31180-6.

31. Zdravkovic M, Berger-Estilita J, Zdravkovic B, Berger D. Scientific quality of COVID-19 and SARS CoV-2 publications in the highest impact medical journals during the early phase of the pandemic: a case control study. PLoS One. 2020;15(11):e0241826.

32. Feng F, Tuchman S, Denninger JW, Fricchione GL, Yeung A. Qigong for the prevention, treatment, and rehabilitation of COVID-19 infection in older adults. Am J Geriatr Psychiatry. 2020;28(8):812-819.

33. Wayne DB, Green M, Neilson EG. Medical education in the time of COVID-19. Sci Adv. 2020;6(31):eabc7110.

34. Vogus TJ, Rothman NB, Sutcliffe KM, Weick KE. The affective foundations of high-reliability organizing. J Organ Behav. 2014;35(4):592-596.

35. Emanuel EJ. The inevitable reimagining of medical education. JAMA. 2020;323(12):1127-1128

36. Han H, Resch DS, Kovach RA. Educational technology in medical education. Teach Learn Med. 2013;25 Suppl l:S39-S43.

37. Prober CG, Khan S. Medical education reimagined: a call to action. Acad Med. 2013;88(10):1407-1410. 
38. Boulet J, Bede C, McKinley D, Norcini J. An overview of the world's medical schools. Med Teach. 2007;29(1): $20-26$

39. Gruenewald DA. The best of both worlds: a critical pedagogy of place. Environ Educ Res. 2008;14(3): 308-324.

40. Lave J, Wenger E. Situated learning: legitimate peripheral participation. Cambridge, UK: Cambridge University Press; 1991.

41. Dornan T, Boshuizen H, King N, Scherpbier A. Experience-based learning: a model linking the processes and outcomes of medical students' workplace learning. Med Educ. 2007;41(1):84-91.

42. Jacobs RL. Structured on-the-job training: unleashing employee expertise in the workplace. 2nd ed. San Francisco, USA: Berrett-Koehler Publishers; 2003.

43. Han H, Roberts NK, Korte R. Learning in the real place: medical students' learning and socialization in clerkships at one medical school. Acad Med. 2015;90(2):231-239.

44. Miller DG, Pierson L, Doernberg S. The role of medical students during the COVID-19 pandemic. Ann Intern Med. 2020;173(2):145-146.

45. Medical Schools Council. MSC issues statement of expectation for medical student volunteers in the NHS. https://www.medschools.ac.uk/news/msc-issues-statement -of-expectation-for-medical-student-volunteers-in-the-nhs. Published March 2020. Accessed August 5, 2021.

46. Compton S, Sarraf-Yazdi S, Rustandy F, Radha Krishna LK. Medical students' preference for returning to the clinical setting during the COVID-19 pandemic. Med Educ. 2020;54(10):943-950.

47. Mahon KE, Henderson MK, Kirch DG. Selecting tomorrow's physicians: the key to the future health care workforce. Acad Med. 2013;88(12):1806-1811.

48. Tarmey D, Wood DF, Lillicrap MS, Canuto HC. Should medical schools relax academic admission criteria? BMJ. 2019;367:16456.

49. Talamantes E, Henderson MC, Fancher TL, Mullan F. Closing the gap: making medical school admissions more equitable. N Engl J Med. 2019;380(9):803-805.

50. Bhugra D. Medicine's contract with society. J R Soc Med. 2014;107(4):144-147.

51. Poole KG Jr, Jordan BL, Bostwick JM. Mission drift: are medical school admissions committees missing the mark on diversity? Acad Med. 2020;95(3):357-360. 